\title{
THE COMPARISON OF PRESSED SEED OILS FEATURES
}

Vladimír MAŠÁN, Department of Horticultural Machinery, Faculty of Horticulture, Mendel University in Brno, Valtická 337 , Lednice, 691 44, Czech Republic, vladimir.masan@mendelu.cz (corresponding author)

Patrik BURG, Department of Horticultural Machinery, Faculty of Horticulture, Mendel University in Brno, Valtická 337, Lednice, 691 44, Czech Republic, patrik.burg@mendelu.cz

Miroslav HORÁK, Department of Post-Harvest Technology of Horticultural Products, Faculty of Horticulture, Mendel University in Brno, Valtická 337, Lednice, 691 44, Czech Republic, miroslav.horak@mendelu.cz

Petr ŠNURKOVIČ, Department of Post-Harvest Technology of Horticultural Products, Faculty of Horticulture, Mendel University in Brno, Valtická 337, Lednice, 691 44, Czech Republic, petr.snurkovic@mendelu.cz.

\begin{abstract}
The grape seed oils are characteristic by a very high content of substances. However, a lipid oxidation is the fundamental problem of the seed oils quality degradation. The important indicator for determining the specific type's purity, stability and level of oil degradation might be its colour parameter. The aim of this study was to identify the different varieties of oils, to evaluate its development during storage and to identify changes in different pressed seed oils. The CIELAB method and NIR spectroscopy were used during the research. Its main advantages include speed, accuracy and simplicity. The use of NIR seemed to be unsuitable as it could not reliably identify different kinds of grape seed oils. Only three kinds of grape seed oils out of six were identified. Contrary, the colour values obtained, using the CIELAB method, correlated significantly with the maturity of the individual varieties. This method can help to verify the authenticity of the oil. The CIELAB method also enabled colour changes in storage. The results show that after six months of storage, the oil got browner and the $L^{*}$ value had decreased. After another 6 months, the shift in values was not so significant. Similarly, the values of other parameters had changed. Using the CIELAB method can be recommended for testing of larger sample sizes for future use in the evaluation of the authenticity and quality of seed oils. The CIELAB method will not replace the standard methods but it might be used for pre-selection of tested samples.
\end{abstract}

Keywords: CIELAB method, colour parameter, grape seed oils, NIR spectroscopy, oil degradation

\section{INTRODUCTION}

Oil from grape seeds is commercialized as a food as well as a substance for cosmetic and pharmaceutical applications (Fiori, 2007). Products of selected seed oils are an interesting raw material in the food industry for its dietary value (Nyam et al., 2009). It has a high content of essential fatty acids and tetraphenols (Anastasiadis et al., 2010). The production of these oils in Czech Republic and abroad as well has been growing significantly and it opens up new possibilities for vineyard and winery operations in the application of the residual primary products (Dědina et al., 2013).

Important to mention as well, is higher selling price compared with regular vegetable oils. For each product on the market there must be guarantee of the genuineness and typicality of it, watched by the quality control of foods (Giuffrida et al., 2011). These parameters can influence consumers in their purchase decisions (Ranalli et al., 2005; Aparicio and Aparicio-Ruíz, 2000). An important indicator for determining the variety's purity, stability and oil degradation due to storage is their colour intensity (Criado et al., 2008). Moyano et al. (2008) claim that the colour intensity of oils is among others related to the content of healthy substances, e.g. anthocyanins (Liang et al., 2011).

A variety of methods can be used for evaluation of colour intensity of oils. For example, Moyano et al. (2008) and Vik (2015) claim that the best method for the assessment of colour intensity of olive oil is the CIELAB method, which is fast, inexpensive, and objective. Nyam et al. (2009) had successfully used this method to compare selected seed oils. Moreover, Meléndez-Martínez et al. (2007) claim that this method is suitable for long-term examinations of a large number of analysed oil samples.

In recent years, it is possible to observe a rapid progress in the application of NIR spectroscopy - a method that enables to measure the quality of horticultural products without any destruction of fruit (Bobelyn et al., 2010). NIR spectroscopy is widely used as an alternative method to the so called wet chemistry. It is used for both quantitative and qualitative analyses (Burns and Ciurczak, 2008). Its main advantages are speed, accuracy and simplicity of individual estimations (Liu, 2011). However, when estimating content substances in individual samples, it is necessary to carry out an exact calibration of the NIR spectrometer on the base of a suitable set of calibration standards (matrices). The main

Copyright (C) 2017 The Authors. Published by Aleksandras Stulginskis University. This is an open-access article distributed under the terms of the Creative Commons Attribution License (CC-BY 4.0), which permits unrestricted use, distribution, and reproduction in any medium, provided the original author and source are credited. 
disadvantages of this method are the dependence on reference methods and a weak sensitivity to minor components (Büning, 2003).

Both analysis can be selected and used in order to reach more comprehensive and precise results. For the target consumers, the colour intensity of oils is the only evaluable parameter that can be biased by partially subjective approach.

The aim of this paper is to verify the possibility of using colour system method (the CIELAB method) and NIR spectroscopy to identify difference in colour in grape seed oils and cheaper vegetable oils.

\section{MATERIAL AND METHODS}

\section{Samples}

For the purpose of this paper, six varieties of grape seeds were used. All of them were grown in Czech republic, wine region of Moravia, wine sub-region Velké Pavlovice, town Čejkovice, producer Víno Sýkora s.r.o.. The varieties included Dornfelder (DR), Blaufränkisch (BF), Pálava (PA), Riesling (RR), Pinot Gris (PG), and Zweigelt (ZW). The oil was pressed on the screw press UNO FM 3F by the Farmet Company, Czech Republic. This press model is designed for cold pressing of all oily seeds. The speed of the screw press was at $80 \mathrm{rpm}$ (this speed is commonly used by the producers of oils) and the nozzle of average size $10 \mathrm{~mm}$. From each variety of grapes, 3 oil samples were pressed out, each of them with 1-hour delay. After pressing, the oils were settled by gravity, then filtered and poured into glass jars (volume 500 $\mathrm{ml}$ ). Oils were not technologically treated or stabilized in any way. The samples were then evaluated using the NIR spectroscopy and CIELAB method. Another evaluation was carried out after six and twelve months of storage in conditions of absence of light at $12^{\circ} \mathrm{C}$.

\section{The NIR measurements}

NIR spectra were measured by the instrument Antaris II, using the OMNIC software. This program enables not only to setup suitable parameters of the spectrometer and to control the course of the measuring but also to adjust and analyse measured spectra. Each sample was measured twice, in two batches and the resulting spectra were pooled to obtain an average spectrum. The NIR spectra were measured as an attenuation of light after passing through the sample (transmission measuring) placed in a quartz cell Suprasil, Type 110-QS. The measurements were performed under the following conditions: no. of scans 50, resolution $16 \mathrm{~cm}^{-1}$, spectral range $4000-10000 \mathrm{~cm}^{-1}$, gain $1 \mathrm{x}$, InGaAs detector, $\mathrm{CaF}_{2}$ beamsplitter.

The analysis of measured spectra was performed using the chemometric package TQ Analyst and algorithm Discriminant Analysis. This spectral technique enables to determine the classes that are the most similar to the unknown material. There are several classes in the calibration model and each of them is described by means of a deliberate number of standards (at least two) (Downey, 1996).

\section{CIELAB measurements}

Colour changes in the oils were monitored by determining transmittance on the Lovibond RT850i (X-rite Incorporated, USA), in 3 repeated measurements for each variety. The resulting colour was defined as a colour space $L^{*}$ $a^{*} b^{*}$. Oil samples were measured in plastic cuvettes with $10-\mathrm{mm}$ optical path length. The evaluation was carried out by OnColor ${ }^{\mathrm{TM}}$ Premium software application by Lovibond. The differences between the colour changes of the individual samples were expressed through the colour difference $\Delta E^{*} a b$ in colour space $L^{*} a^{*} b^{*}$, which indicates the size of the difference but not its direction. It is defined by the following equation:

$$
\Delta E^{*} a b=\sqrt{\left(\Delta L^{*}\right)^{2}+\left(\Delta a^{*}\right)^{2}+\left(\Delta b^{*}\right)^{2}}
$$

where: $\Delta L^{*}, \Delta a^{*}$, and $\Delta b^{*}$ are the differences of these values between the samples just after pressing and after six (twelve) months of storage.

\section{Statistics}

A statistical analysis was carried out using the software package 'Statistica 12.0' (StatSoft Inc., USA). Moreover, the standard deviation and Spearman's correlation analysis was used. For all statistical tests, a 95\% confidence level was used.

\section{RESULTS AND DISCUSSION}

\section{The NIR spectroscopy}

Ferrer-Gallego et al. (2010) explored the possibilities of distinguishing different grape varieties from different regions by comparing the flavanols contents of samples, by using the NIR spectroscopy. The results indicated the use in order to distinguish between possible vineyards of origin. Techniques based on spectral data have been applied to determine composition, characterization and detection of adulterations of oil in work of authors Rohman and Man, (2011), Rodríguez-Pulido et al. (2013), Luna et al. (2013), Pizarro et al. (2013). The partial results by using the NIR spectroscopy achieved Yang et al. (2005) as well.

According to Szłyk et al. (2005), the NIR spectroscopy can be applied in quality control of edible oils and fats to monitor their oxidative stability in routine analyses. 


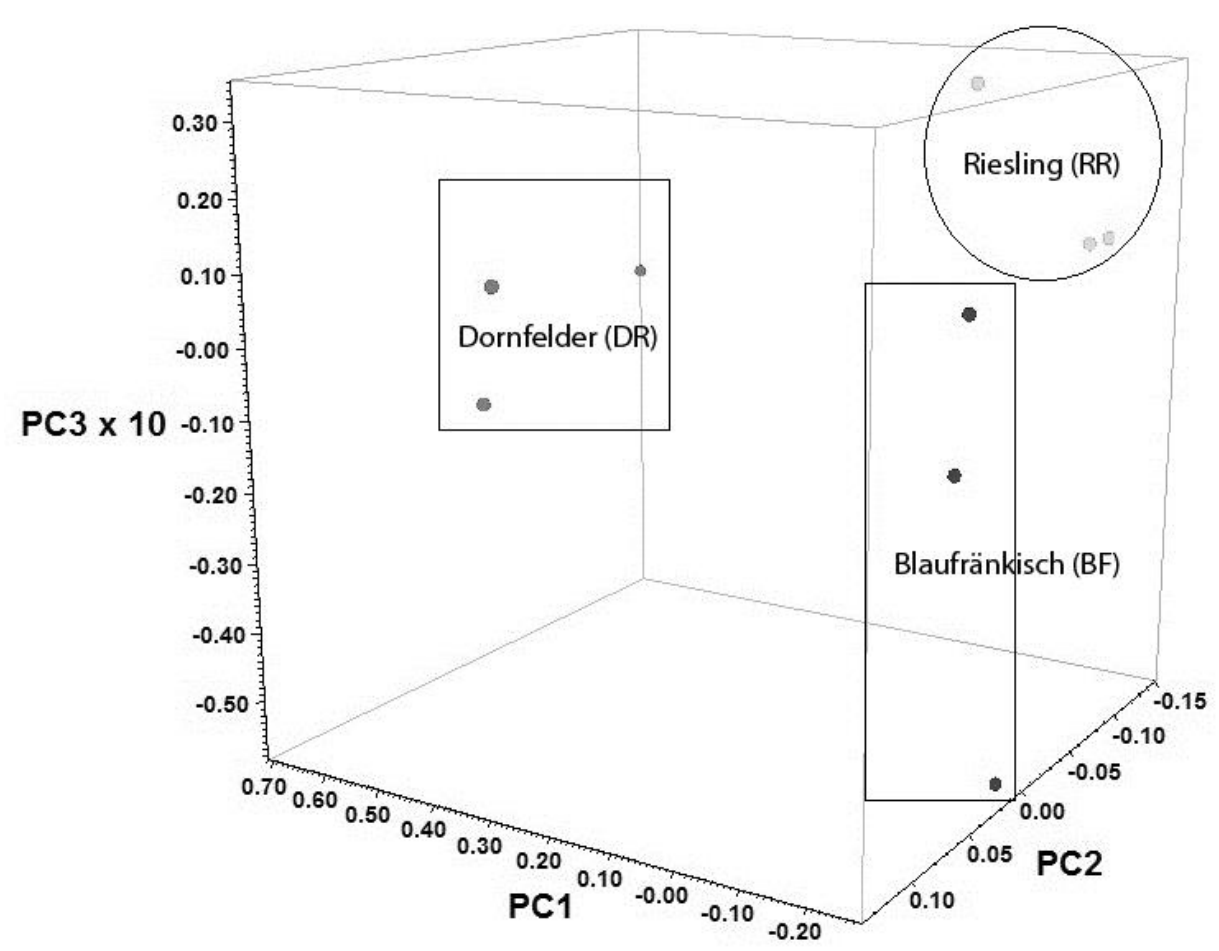

Figure 1. Distribution of Oil Classes measured using Principal component score 3D display using the TQ Analyst software.

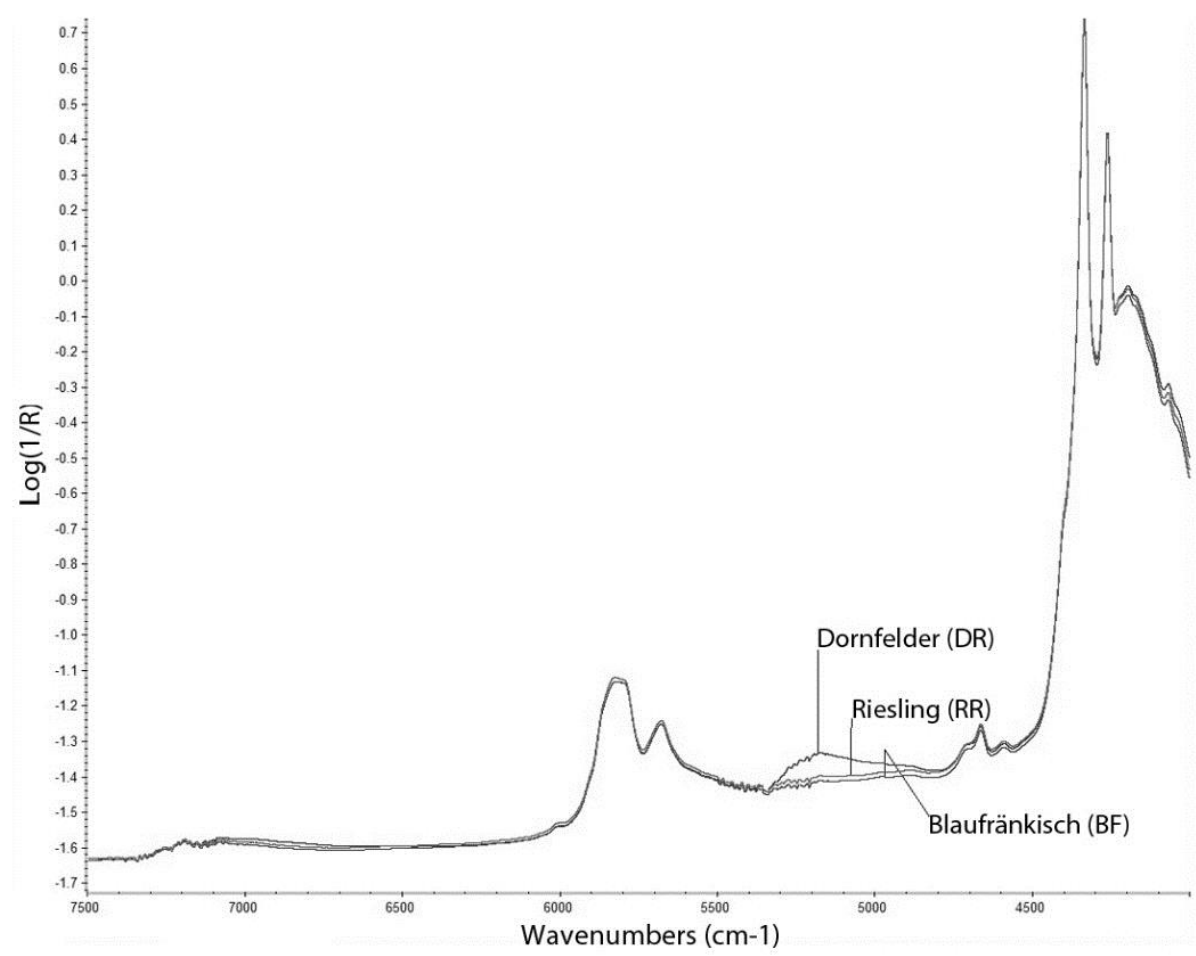

Figure 2. Spectrums Grape Seed Oils measured using the OMNIC software

The spectrums of selected oils were divided into individual clusters by the discriminatory analysis. The differences can be found between them, as it can be seen from Figures 1 and 2, on which the differences between spectra are clearly distinct.

Other varieties could not be identified by the above-mentioned methods due to the minimal spectrum differences between varieties. For this reason, NIR spectroscopy cannot be recommended for use of the purpose of identifying the varietal purity of grape seed oils.

\section{The CIELAB method - Colour assessment}

Table 1 shows the average measured values of the six monitored varieties. The measurements did not show significant differences between white and red groups of varieties. However, the obtained results confirm a relatively wide 
range of hue values $(h a b)$ and chroma $\left(C^{*} a b\right)$, which is typical for these oils. The grape seed oils show greater shade balancewhen compared with the results by Moyano et al. (2008) and their virgin olive oil samples in parameters hue ( $h a b)$ and chroma $\left(C^{*} a b\right)$. In parameter lightness $\left(L^{*}\right)$ reported authors similar results.

The factors hue $(h a b)$ and chroma $\left(C^{*} a b\right)$ of the DR and RR varieties were both at the ends of the spectrum. In the lightness factor $\left(L^{*}\right)$ it was again the DR and ZW varieties.

Table 1 Average values of measurements of grape seed oils using the CIELAB method $(n=3)$.

\begin{tabular}{|c|c|c|c|c|c|c|c|c|c|c|c|c|}
\hline \multicolumn{13}{|c|}{ First measurement } \\
\hline $\begin{array}{l}\text { The order of } \\
\text { maturation }\end{array}$ & Var. & $L^{*}$ & $\begin{array}{c}L^{*} \\
\text { STD } \\
\end{array}$ & $a^{*}$ & $\begin{array}{c}a^{*} \\
\text { STD } \\
\end{array}$ & $b^{*}$ & $\begin{array}{c}b^{*} \\
\text { STD } \\
\end{array}$ & $C^{*}$ & $\begin{array}{c}C^{*} \\
\mathrm{STD} \\
\end{array}$ & $h^{\circ}$ & $\begin{array}{c}h^{\circ} \\
\text { STD } \\
\end{array}$ & $\Delta E^{*} a b$ \\
\hline 1 & DR & 77.65 & 0.06 & 5.55 & 0.02 & 111.67 & 0.00 & 111.81 & 0.00 & 87.15 & 0.02 & - \\
\hline 2 & PG & 86.87 & 0.01 & -2.75 & 0.00 & 79.36 & 0.00 & 79.40 & 0.00 & 91.99 & 0.02 & - \\
\hline 3 & ZW & 90.53 & 0.02 & -1.83 & 0.00 & 75.81 & 0.00 & 75.83 & 0.00 & 91.39 & 0.01 & - \\
\hline 4 & PA & 89.87 & 0.02 & -2.34 & 0.03 & 81.96 & 0.00 & 82.00 & 0.00 & 91.64 & 0.02 & - \\
\hline 5 & $\mathrm{BF}$ & 86.52 & 0.02 & -3.09 & 0.01 & 71.56 & 0.00 & 71.63 & 0.00 & 92.47 & 0.01 & - \\
\hline 6 & $\mathrm{RR}$ & 89.77 & 0.01 & -4.75 & 0.02 & 63.52 & 0.00 & 63.69 & 0.00 & 94.26 & 0.01 & - \\
\hline \multicolumn{13}{|c|}{ Measured after 6 months } \\
\hline $\begin{array}{c}\text { The order of } \\
\text { maturation }\end{array}$ & Var. & $L^{*}$ & $\begin{array}{c}L^{*} \\
\text { STD } \\
\end{array}$ & $a^{*}$ & $\begin{array}{c}a^{*} \\
\text { STD } \\
\end{array}$ & $b^{*}$ & $\begin{array}{c}b^{*} \\
\text { STD } \\
\end{array}$ & $C^{*}$ & $\begin{array}{c}C^{*} \\
\mathrm{STD} \\
\end{array}$ & $h^{\circ}$ & $\begin{array}{c}h^{\circ} \\
\text { STD } \\
\end{array}$ & $\Delta E^{*} a b$ \\
\hline 1 & DR & 44.40 & 0.01 & 13.02 & 0.01 & 75.60 & 0.17 & 76.71 & 0.17 & 80.23 & 0.03 & 49.61 \\
\hline 2 & PG & 65.89 & 0.05 & 10.42 & 0.02 & 108.63 & 0.11 & 109.13 & 0.11 & 84.52 & 0.01 & 38.36 \\
\hline 3 & ZW & 77.29 & 0.02 & 10.94 & 0.02 & 124.86 & 0.22 & 125.34 & 0.22 & 84.99 & 0.02 & 52.39 \\
\hline 4 & $\mathrm{PA}$ & 73.15 & 0.02 & 10.71 & 0.01 & 119.46 & 0.14 & 119.94 & 0.14 & 84.88 & 0.01 & 43.09 \\
\hline 5 & $\mathrm{BF}$ & 63.62 & 0.02 & 10.36 & 0.01 & 104.62 & 0.18 & 105.13 & 0.17 & 84.35 & 0.02 & 42.41 \\
\hline 6 & RR & 71.13 & 0.00 & 8.11 & 0.02 & 113.15 & 0.02 & 113.44 & 0.02 & 85.90 & 0.01 & 54.55 \\
\hline \multicolumn{13}{|c|}{ Measured after 12 months } \\
\hline $\begin{array}{l}\text { The order of } \\
\text { maturation }\end{array}$ & Var. & $L^{*}$ & $\begin{array}{c}L^{*} \\
\text { STD }\end{array}$ & $a^{*}$ & $\begin{array}{l}a^{*} \\
\text { STD }\end{array}$ & $b^{*}$ & $\begin{array}{c}b^{*} \\
\text { STD }\end{array}$ & $C^{*}$ & $\begin{array}{c}C^{*} \\
\text { STD }\end{array}$ & $h^{\circ}$ & $\begin{array}{c}h^{\circ} \\
\text { STD }\end{array}$ & $\Delta E^{*} a b$ \\
\hline 1 & DR & 43.68 & 0.01 & 12.82 & 0.03 & 74.40 & 0.06 & 75.49 & 0.06 & 80.22 & 0.02 & 50.95 \\
\hline 2 & PG & 64.05 & 0.02 & 9.81 & 0.02 & 105.50 & 0.12 & 105.95 & 0.12 & 84.69 & 0.01 & 36.90 \\
\hline 3 & ZW & 74.25 & 0.00 & 10.63 & 0.01 & 120.40 & 0.10 & 120.87 & 0.10 & 84.96 & 0.01 & 49.08 \\
\hline 4 & PA & 72.70 & 0.01 & 10.59 & 0.02 & 118.75 & 0.09 & 119.22 & 0.09 & 84.90 & 0.01 & 42.61 \\
\hline 5 & $\mathrm{BF}$ & 63.91 & 0.01 & 10.03 & 0.00 & 105.09 & 0.15 & 105.57 & 0.14 & 84.55 & 0.01 & 42.52 \\
\hline 6 & $\mathrm{RR}$ & 68.44 & 0.00 & 7.67 & 0.02 & 108.73 & 0.20 & 109.00 & 0.20 & 85.97 & 0.02 & 51.51 \\
\hline
\end{tabular}

\section{Ripening stage}

Table 1 shows the average values of the first measurement after pressing as well as the second and third measurement after six and then twelve months of storage. When comparing the values of the two measurements for each variety (after 6 months and 12 months), the overall darkening of oils and the lower $L^{*}$ values become obvious.

Moyano et al. (2008) and Criado et al. (2007) presented similar results. Significant changes of value were recorded in the factor $b^{*}$, which represents intensifying of yellow colour. This change corresponds with a decrease in lightness $\left(L^{*}\right)$. The DR variety was the only one, where there was a drop in the $b^{*}$ value from the original 111.67 to 75.60 . In combination with the most significant decrease of lightness $\left(L^{*}\right)$, after six months of storage, this variety was the darkest. The measure of colour difference, defined as deviation delta $\mathrm{E}(\Delta E)$ for each oil stored for six months reached relatively high levels. Vik (1995) reported that values greater than three units express colour difference that can be perceived visually by the human eye. The results in Table 1 show that the smallest influence of the storage on the colour was found in the oil from the seeds of PG variety, while the largest changes were observed in the RR variety. The change in colour after another 6 months was not that significant anymore, on the other hand, it was more stable.

Comparison with the results by Moyano et al. (2008) and Criado et al. (2007 and 2008), it is proved that the change in the colour of grape seed oils is more pronounced than in virgin olive oils. The claim of Dufossé et al. (2005), that the change of colour depends on the length of storage, were confirmed.

\section{The maturing of varieties}

Table 2. The correlation between the order of maturation lenght and each parameter of CIELAB method $(n=3)$.

\begin{tabular}{ccc}
\hline Correlation & Spearman R & $\mathrm{t}(\mathrm{N}-2)$ \\
\hline Nrvs. $L^{*}$ & 0.35 & 1.48 \\
Nrvs. $a^{*}$ & $-0.83^{*}$ & $-5.97^{*}$ \\
Nr vs. $b^{*}$ & $-0.82^{*}$ & $-5.69^{*}$ \\
Nrvs. $C^{*}$ & $-0.82^{*}$ & $-5.69^{*}$ \\
Nr vs. $h^{\circ}$ & $0.79^{*}$ & $5.10^{*}$ \\
\hline
\end{tabular}

\footnotetext{
$*$ correlation is significant at the 0.05 level
} 
Another parameter examined was the influence of the maturation on the colour characteristics of the oil. According to our previous research (Mašán, 2017), the greatest influence on the characteristics of oil has the variety of seeds and the date of harvesting. The same conclusion was reached by Ohnishi et al. (1990) and George and Cenkowski (2007).

The results have shown the significant dependence on the variety maturation length and parameters $a^{*}, b^{*}, C^{*}$ a $h^{\circ}$. The dependence of parameter $L^{*}$ was low.

\section{CONCLUSION}

The obtained results from evaluation of six varieties of grape seed oils confirm a relatively wide range of hue values $(h a b)$ from 87.15 to 94.26 and chroma $\left(C^{*} a b\right)$ from 111.81 to 63.69 , that is typical for these oils. Measurements did not show significant differences between oils from seeds of white and red groups of varieties. The CIELAB method system gave also good results for differentiation of colour varieties of grape seed oils in dependence on the maturation. The results had shown significant dependence on the level of $\mathrm{R}=0,82$. When comparing the values of the two measurements for each variety (one after 6 months of storage and one after 12 months of storage), the overall darkening of oils and lowering $L^{*}$ values become obvious. The measure of colour difference, defined as deviation delta $\mathrm{E}(\triangle E)$ for each oil stored for six months, reached relatively high levels (numbers between 38.36-54.55). The total darkening of oil after 6 months was in between $14.6 \%$ until $42.8 \%$ and after 12 months it became from $18.0 \%$ until $43.7 \%$.

By using the NIR spectroscopy, only three varieties of grape seed oils had been identified, specifically Dornfelder, Blaufränkisch and Riesling. Therefore, the use of NIR spectroscopy method had proven to be unsuitable as it could not reliably identify various kinds of grape seed oils.

\section{ACKNOWLEDGMENTS}

Financial support for this research was provided by project IGA ZF MENDELU Brno, project ID: IGA-ZF/2017-DP004.

\section{REFERENCES}

1. Anastasiadi, A., Pratsinis, H., Kletsas, D., Skaltsounis, A.L., Haroutounian, S.A. 2010. Bioactive non-coloured polyphenols content of grapes, wines and vinification by-products: Evaluation of the antioxidant activities of their extracts. Food Research International, Vol. 43, pp. 805-813. https://doi.org/10.1016/j.foodres.2009.11.017

2. Aparicio, R., Aparicio-Ruíz, R. 2000. Authentication of vegetable oils by chromatographic techniques. Journal of Chromatography A, Vol. 881, pp. 93-104. https://doi.org/10.1016/j.postharvbio.2009.09.006

3. Bobelyn, E., Serban, A., Nicu, M., Lammertyn, J., Nicolai, B., Saeys, W. 2010. Postharvest quality of apple predicted by NIRspectroscopy: Study of the effect of biological variability on spectra and model performance. Postharvest Biology and Technology, Vol. 55, pp. 133-143.

4. Burns, D. A., Ciurczak, E. W. 2008. Handbook of near-infrared analysis 3rd ed., CRC Press Inc, Bosa Roca, United States.

5. Büning, H., 2003: Analysis of water in food by near infrared spectroscopy. Food Chemistry, vol. 82, pp. 107-115. https://doi.org/10.1016/S0308-8146(02)00583-6

6. Criado, M.N., Motilva, M.J., Goñi, M., Romero, M.P. 2007. Comparative study of the effect of the maturation process of the olive fruit on the chlorophyll and carotenoid fractions of drupes and virgin oils from Arbequina and Farga cultivars. Food Chemistry, Vol. 100, pp. 748-755. https://doi.org/10.1016/j.foodchem.2005.10.035

7. Criado, M.N., Romero, M.P., Casanovas, M., Motilva, M.J. 2008. Pigment profile and colour of monovarietal virgin olive oils from Arbequina cultivar obtained during two consecutive crop seasons. Food Chemistry, Vol. 110, pp. 873-880. https://doi.org/10.1016/j.foodchem.2008.02.075

8. Dědina, M., Skala, O., Lachman, J., Hejtmánková, A. 2013. Pressing of oils from grape wine seeds (in Czech), 1. ed., VUZT, v.v.i., Praha, Czech Republic.

9. Downey, G. 1996. Review: Authentication of food and food ingredients by near infrared spectroscopy. Journal of Near Infrared Spectroscopy, Vol. 4, pp. 47-61. https://doi.org/10.1255/jnirs.75

10. Dufossé, L., Galaup, P., Carlet, E., Flamin, C., Valla, A. 2005. Spectrocolorimetry in the CIE L*a*b* color space as useful tool for monitoring the ripening process and the quality of PDO red-smear soft cheeses. Food Research International, Vol. 38, pp. 919-924. https://doi.org/10.1016/j.foodres.2005.02.013

11. Ferrer-Gallego, R., Hernández-Hierro, J.M., Rivas-Gonzalo, J.C., Escribano-Bailón, M.T. 2010. Feasibility study on the use of near infrared spectroscopy to determine flavanols in grape seeds. Talanta, Vol. 82, pp. $1778-1783$. https://doi.org/10.1016/j.talanta.2010.07.063

12. Fiori, L. 2007. Grape seed oil supercritical extraction kinetic and solubility data: critical approach and modeling. Journal of Supercritical Fluids, Vol. 43, pp. 43-54. https://doi.org/10.1016/j.supflu.2007.04.009

13. George, St.S. D., Cenkowski, S. 2007. Influence of harvest time on the quality of oil-based compounds in sea buckthorn (Hippophae rhamnoides L. ssp. sinensis) seed and fruit. Journal of Agricultural and Food Chemistry, Vol. 55, pp. 8054-8061. https://doi.org/10.1021/jf070772f

14. Giuffrida, D., Salvo, F., Salvo, A., Cossignani, L., Dugo, G. 2011. Pigments profile in monovarietal virgin olive oils from various Italian olive varieties. Food Chemistry, Vol. 124, pp. 1119-1123. https://doi.org/10.1016/j.foodchem.2010.07.012

15. Liang, Z., Sang, M., Fan, P., Wu, B., Wang, L., Yang, S., Li, S. 2011. CIELAB Coordinates in Response to Berry Skin Anthocyanins and Their Composition in Vitis. Journal of Food Science, Vol. 76, pp. C490-C497. https://doi.org/10.1111/j.17503841.2011.02095.x

16. Liu, F., He, Y., Wang, L., Sun, G., 2011: Detection of OrganicAcids and pH of Fruit Vinegars Using Near-Infrared Spectroscopy 
and Multivariate Calibration. Food Bioprocess Technol, Vol. 4, pp. 1331-1340. https://doi.org/10.1007/s11947-009-0240-9

17. Luna, A. S., da Silva, A. P., Ferre, J., Boque, R. 2013. Classification of edible oils and modeling of their physico-chemical properties by chemometric methods using mid-IR spectroscopy. Spectrochim. Acta A, Vol. 100, pp. $109-114$. https://doi.org/10.1016/j.saa.2012.06.034

18. Mašán, V., Burg, P., Rutkowski, K., Burgová, J., Lampíř, L., Višacki, V. 2017. Seed oil content and selected qualitative parameters of oils from grape seeds. Potravinarstvo, Vol. 11, pp. 629-633. https://doi.org/10.5219/810

19. Meléndez-Martínez, A. J., Vicario, I. M., Heredia, F. J. 2007. Rapid assessment of vitamin A activity through objective color measurements for the quality control of orange juices with diverse carotenoid profiles. Journal of Agriculture and Food Chemistry, Vol. 55, pp. 2808-2815. https://doi.org/10.1021/jf0635412

20. Moyano, M. J., Meléndez-Martínez, A. J., Alba, J., Heredia, F. J. 2008. A comprehensive study on the colour of virgin olive oils and its relationship with their chlorophylls and carotenoids indexes (II): CIELUV and CIELAB uniform colour spaces. Food Research International, Vol. 41, pp. 513-521. https://doi.org/10.1016/j.foodres.2008.03.006

21. Nyam, K. L., Tan, C. P., Lai, O. M., Long, K., Che Man, Y. B. 2009. Physicochemical properties and bioactive compounds of selected seed oils. LWT - Food Science and Technology, Vol. 42, pp. 1396-1403. https://doi.org/10.1016/j.lwt.2009.03.006

22. Pizarro, C., Rodríguez-Tecedor, S., Pérez-del-Notario, N., Díez E. I., González-Sáiz, J. M. 2013. Classification of spanish extra virgin olive oils by data fusion of visible spectroscopic fingerprints and chemical descriptors. Food Chemistry, Vol. 138, pp. 915-922. https://doi.org/10.1016/j.foodchem.2012.11.087

23. Ranalli, A., Malfatti, A., Lucera, L., Contento, S., Sotiriou, E. 2005. Effects of processing techniques on the natural colourings and the other functional constituents in virgin olive oil. Food Research International, Vol. 38, pp. 873-878. https://doi.org/10.1016/j.foodres.2005.02.011

24. Rohman, A., Man, Y. B. C. 2011. Analysis of chicken fat as adulterant in cod liver oil using Fourier Transform Infrared (FTIR) spectroscopy and chemometrics. CyTA - Journal of Food, Vol. 9, pp. 187-191. https://doi.org/10.1080/19476337.2010.510211

25. Rodríguez-Pulido, F. J., Barbin, D. F., Sun, D. W., Gordillo, B., González-Miret, M. L., Heredia, F. J. 2013. Grape seed characterization by NIR hyperspectral imaging. Postharvest Biology and Technology, Vol. 76, pp. 74-82. https://doi.org/10.1016/j.postharvbio.2012.09.007

26. Szłyk, E., Szydłowska-Czerniak, A., Kowalczyk-Marzec, A. 2005. NIR Spectroscopy and Partial Least-Squares Regression for Determination of Natural $\alpha$-Tocopherol in Vegetable Oils. Journal of Agricultural and Food Chemistry, Vol. 53, pp. $6980-6987$. https://doi.org/10.1021/if050672e

27. Vik, M. 2015. Measurement of color and appearance in industrial practice (in Czech), VÚTS, a.s., Liberec. Czech Republic.

28. Yang, H., Irudayaraj, J., Paradkar, M. 2005. Discriminant analysis of edible oils and fats by FTIR, FT-NIR and FT-Raman spectroscopy. Food Chemistry, Vol. 93, pp. 25-32. https://doi.org/10.1016/j.foodchem.2004.08.039 